\title{
Ergonomics smoke machine for indigenous people in Indonesia
}

\author{
Eko Nurmianto* \\ Department of Industrial Eng., Faculty of Industrial Technology, Institute Teknologi Sepuluh Nopember, Surabaya 60111, Indonesia
}

\begin{abstract}
A participatory process is used in the design of a user-centered smoke machine, resulting in lasting benefits to the community. This program of IbM (Science and Technology for Society) has designed fish fumes that are mobile, portable and environmentally ergonomic, applying appropriate technology about fumigation so as to increase knowledge to the community. This program improve people skills especially in smoked fish production, increase employment in the field of fishery products processing business. With this activity can grow the interest of the community to entrepreneurship for those who have not started a business and will increase its business for those who have started the processing business of fishery processing. Benefits derived from IbM (Science and Technology for Society) program are, among others, reduced air pollution caused by open fish curing system so that air quality environment, especially around fish processing SMEs to be better, can support and strengthen fish processing industry in the coastal area that began to grow and especially support local SMEs, increase the quantity and quality of patents that can be generated from community service activities funded by Directorate General of Higher Education, Ministry of Technology Research and Higher Education, Republic of Indonesia.
\end{abstract}

\section{Introduction}

This study The fish processing industry in several country have produced musculo skeletal disorder, i.e: Swedia [1 4], United States [5, 6], Egypt [7], Malaysia [8], Canada [9], and Norway [10,11]. Among those processing are small-scale industry [12].

The fish processing industry in SubDistrict Brondong Regency of Lamongan (one city of the East Java Province) has been around for a few years but it is still not well developed yet. Lack of capital makes them unable to increase production capacity and limited marketing. They still use traditional technology (Figure 1). In view of such circumstances, there is still an opportunity to increase efficiency and effectiveness through a Small Business Development Program in accordance with the situation and condition of such small-scale industry. The design of management, human resources, production, finance, and design will in turn improve the competitiveness of the small-scale industry.

The existing workforce in SME Fish Production has gained the skills of making fish from years of work experience and transmitted informally. Workers SME Fish Production are 6 people and still have a family relationship. The number of SME workers is only 5 people, so there is no job specialization. The administration system is not yet organized. They are still many concurrent jobs regardless of job specification and job description, so that management functions such as planning, organizing, directing and control are not clear and overlap.
At that time the tool used is a tool for roasting goat satay or chicken satay (Figure 1). The tool is insufficient since it can only burn approximately 20 to 30 fish in one process of fogging fish. Whereas in once the process of curing fish takes approximately one hour, so that less can meet the number of orders from consumers. Besides, this tool has a shortage during the processing of smoked fish, most of the smoke disturb neighbors or the surrounding community or less environmentally friendly (Figure 1).

As an ergonomist with a lifelong interest in indigenous stuff, I'd been fascinated for years by questions such as these: How can fishermen/fisherwomen create such smoke machine while constrained in a kneeling posture? Why do they kneel to smoke fish ? Are they in pain or polluted? What do they love about the traditional way of working, and what would they change if they could ? Based on the above conditions then comes the idea of Ergo-Design of Fish Cultivation Tool (Figure 2-4).

The tool is a stuff to process fish fumes with a capacity of 120 in one process. This tool has a privilege that most of the smoke does not disturb the community (environmentally friendly) is marked by a chimney that is 3 meters high so that smoke can be wasted into the free air and does not disturb the community around SME. Besides, this tool is equipped with a door which can be opened at the front and rear so easy in the placement of fish before and after the process of fogging.

\footnotetext{
* Corresponding author: nurmieko@gmail.com
} 


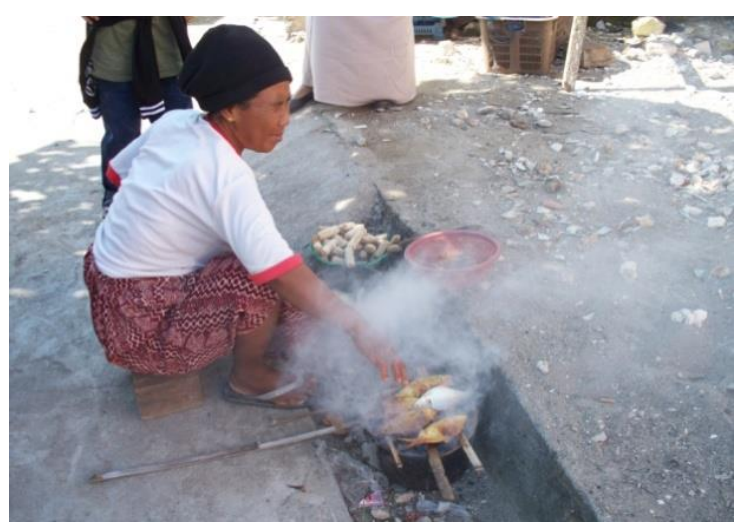

Fig 1. Tools for fish fumigation in previous situation [13].

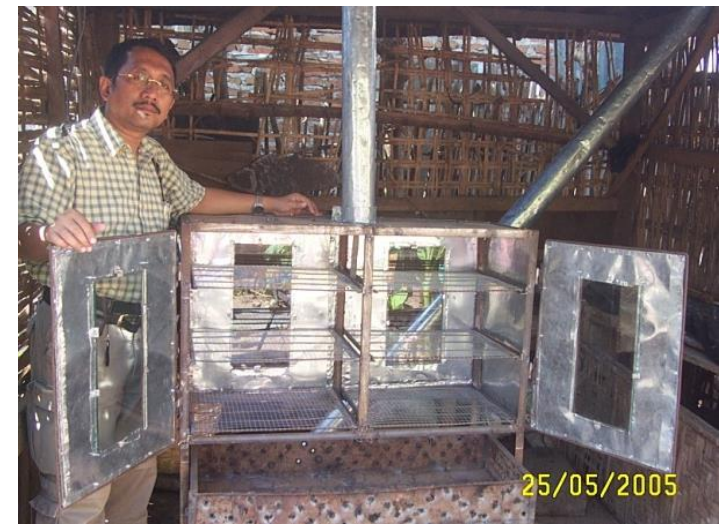

Fig 2. Ergonomic smoke fish tools when first time founded by ergonomic designer [13].

The purpose of this activity are (a) Designing ergonomic smoke machine for fishermen that are mobile, portable and environmentally friendly; (b) Implementing the science of health and safety so as to increase knowledge to the community; (c) Increasing employment in fishery products processing business; (d) With this activity can foster the interest of the community to entrepreneurship for those who have not started a business and will increase its business for those who have started the processing business of fishery processing.

Benefits of this research are: (a) Reduced air pollution caused by open fish curing system so the quality of the air environment especially around the fish processing SMEs for the better, (b) Can support and strengthen fish processing industry that began to grow and especially support local SMEs, (c) Increase the quantity and quality of patents that can be generated from community service activities.

\section{Literature review}

At present, more than $90 \%$ of fishery production in Indonesia is produced by fishermen and $50 \%$ of the yield is traditionally obtained. Increased production of fishery products are generally oriented to economic activities, both increased production in fishery business people and industrial fisheries. Most of the fishery products processing industry still use simple technology and generally still household industry, while large scale industry is generally limited to canning and freezing of fish.

There are various preservation fish [8], among others by salting, drying, fermenting, fermenting and cooling fish. The benefits of eating fish are known to many people, as in Malaysia are the main foods in everyday dishes that provide youthful effects and higher life expectancy than other countries. Processing fish in various ways and flavors causes people to consume more fish.

In conditions where fish seasons reach peak fishermen have difficulty in marketing considering the selling price becomes low. One alternative that can be developed by the fishermen community and their families is to develop a business of local fish-based jerky fish.

\section{Methods of Developing Appropriate Technology}

The success of this program has come from combining appropriate technology with a respectful social process. It illustrates that a systems approach can have an impact well beyond enabling an ergonomist to design a usercentered product. As demonstrated in this article, participation in the systems assessment stimulates endusers to become more aware of themselves and their culture and helps empower them to create meaningful change in their own lives.

The ergonomic smoke machine (ESM) that we designed demonstrates that good ergonomic design can be both simple and human centre design. Indeed, this tool can minimised smoke to be inhaled. It can simply fume the fish untill it cooked. The one knew the fish cooked by obseving via window. The height and thw width is anthropometrically suit with the people in Indonesian costal area [14]. Good design can come from embracing a people's anthropometry cultural, environmental, and economic priorities while applying universal principles to the specific context in which they reside.

Conceptualization. The concept for the ESM evolved from a participatory process that was facilitated by a variety of nonprofit organizations in Lamongan. In two villages we held exploratory meetings with women in their fisherwomen cooperatives and in their homes.

Fumigation Method. Smoking can be done in two ways, namely cold and hot fumigation :

A. Smoking cold (cold smoking). Is the process of fumigation by putting the fish that will be smoked somewhat away from the source of smoke (wood burning), with a temperature of about $40-500 \mathrm{C}$ with a long process of smoking several days to two weeks

B. Smoking hot (hot smoking). Smoking hot (hot smoking) is the process of fumigation where it will be smoked placed close enough to the source asap.Suhu around $70-1000 \mathrm{C}$, the duration of fumigation $2-4$ hours

\section{Results}

Ergonomic Smoke Machine (ESM) for fish curing tool. In the manufacture of Fish Curing Tool required working 
drawings, 3D Auto CAD drawings and photos of the products that have been made, as shown below.

Fish smoke machine specification

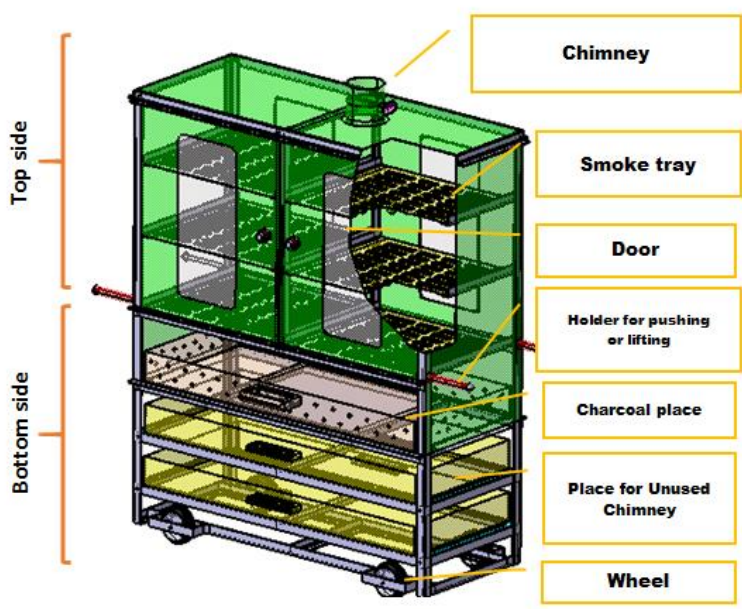

Fig 3. 3-D Smoke Machine

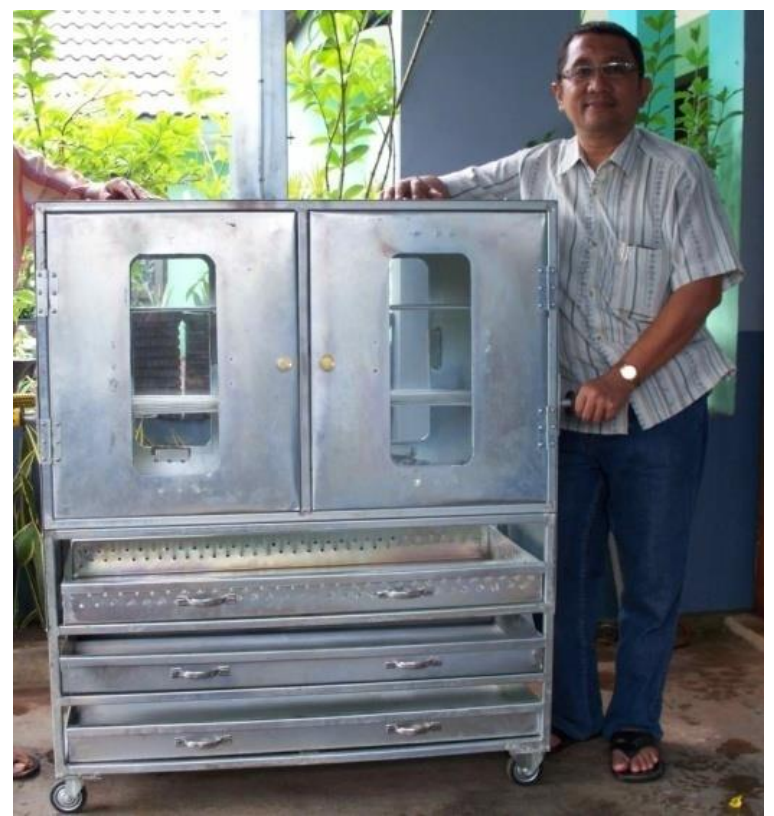

Fig 4. Ergonomic, mobile and portable fish smoke machine.

How to use the fish fumes:

1. Remove the smoke tray and place it on the ground.

2. Place the coconut shell on top of the smoke tray.

3. Burn the coconut shell so that it emits smoke.

4. While waiting for coconut shell charcoal to smoke a bit more, the fish will be smoked, washed, removed the contents of his stomach, and spiced then hung in a tool that has been available smoke.

5. Drawers that have issued a lot of smoke placed in the fish smoke machine so that the smoke can make the fish ripe.

6. Fish maturity level can be observed through glass windows.

7. If the fish is cooked then the smoke is thrown through the chimney by opening the valve.
8. After all the smoke comes out through the chimney then the fish can be taken for the next served

\subsection{Fish smoking training}

This fish smoking training begins with the introduction of tools and how to use it. The training materials comprises of:

- How to use ESM (Ergonomic Smoke Machine) and to process of fishery products.

- Manufacture of smoke fish machine.

- Finance and business management

- Organoleptic (Testing the quality of smoked fish products)

- Packaging and labelling.

- Marketing of smoked fish.

- Entrepreneurship.

\subsection{Appropriate Technology for Society}

Appropriate Technology of Fish Curing Tool is an effective tool to process fish into smoked fish. By using the tool, the Business Group Development of Smoked Fish in Sub District Brondong in Lamongan can run more optimally. From these tools can be smoked various types of fish, chicken, duck and other types of smoke ingredients. And can help people to recognize the smoke fish technology as an alternative to self-employment. Improving community skills is a fish-smoking skill that can be practically demonstrated by the following figures (Figures 5-9):

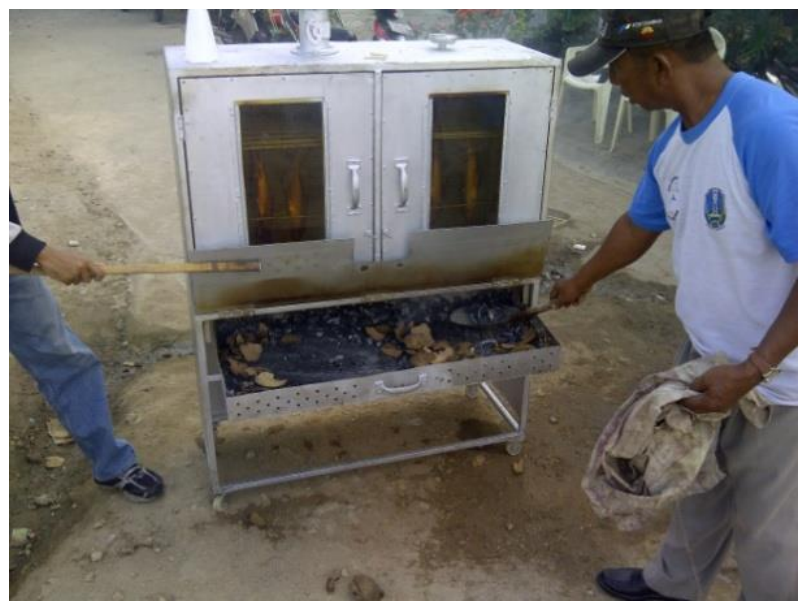

Fig 5. Fishermen test the prototype during the IbM fish cultivation business in Sub-District Brondong in Lamongan city

Two main themes emerged from this research: (1) To be culturally accepted, the ESM (Ergonomic Smoke Machine) would need to be simple and its use intuitively obvious. (2) Because we were designing for people who live in economic poverty, the design would need to balance high quality with low cost.

There were five criteria for economic value $[8,15,16]$ :

a. Robustness, in relation to function;

b. Ergonomic fit, with particular regard to adjustability; 
c. Durability, to withstand local environmental conditions such as dust and humidity with little or no maintenance;

d. Sustainability, to allow local people to use it from locally available materials, fostering community selfreliance and self-sufficiency; and

e. Affordability, so that as many fishermen as possible could acquire the technology without relying on charity.

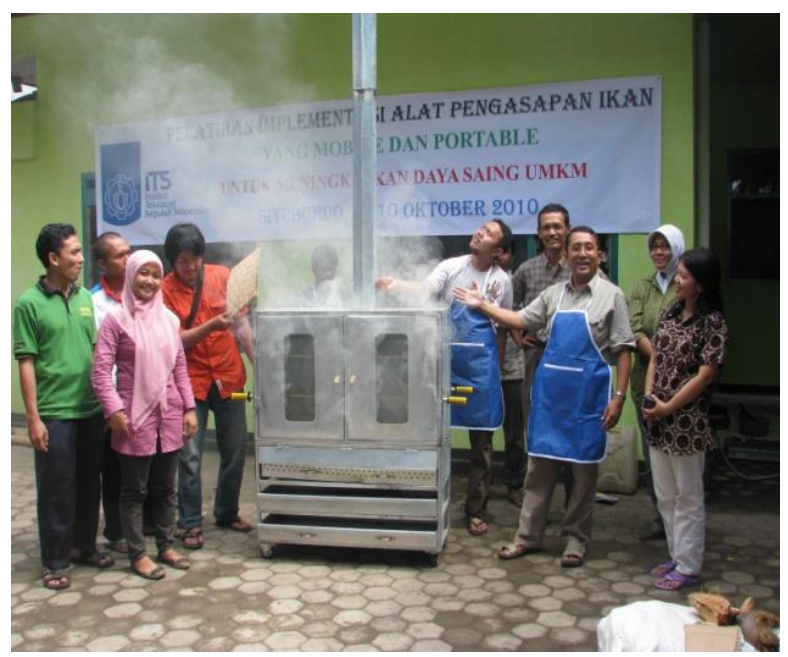

Fig 6. People processing curing fish

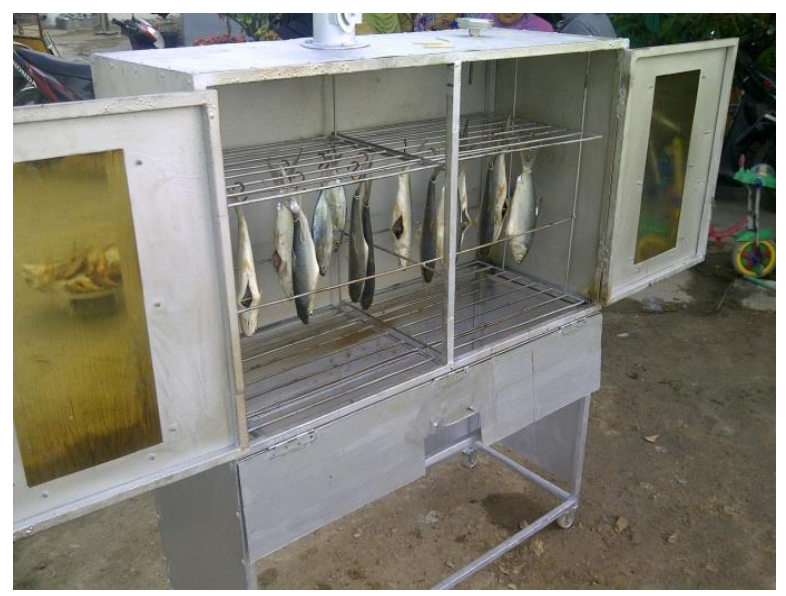

Fig 7. (a) Fish before it is smoked

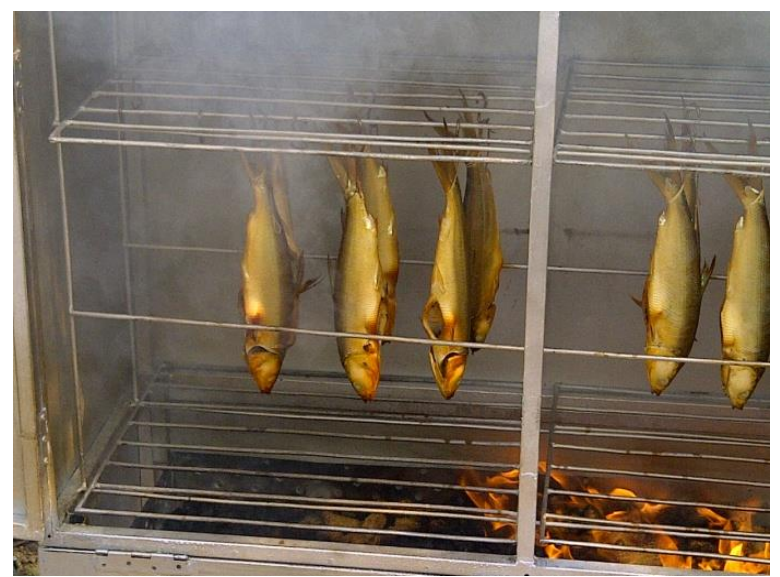

Fig 7. (b) Fish after it is smoked

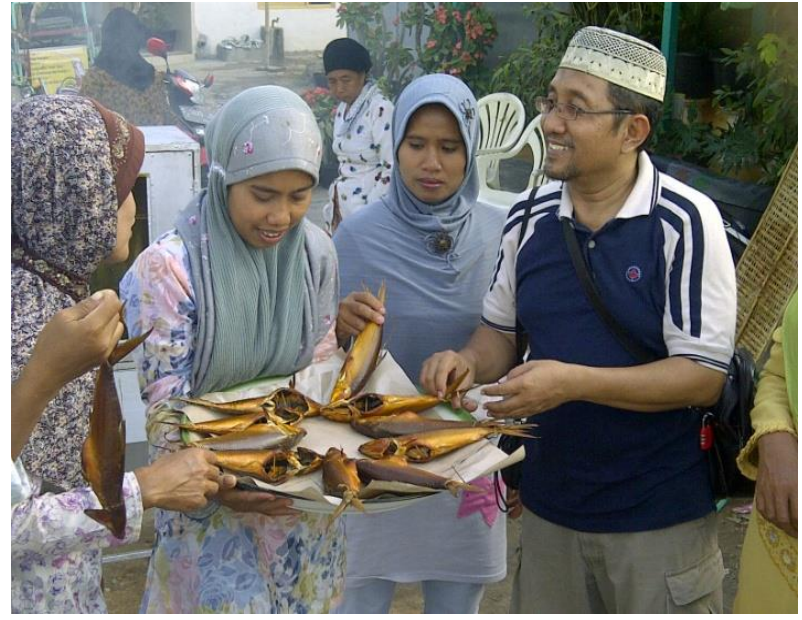

Fig 8. The smoked fish is ready to be served

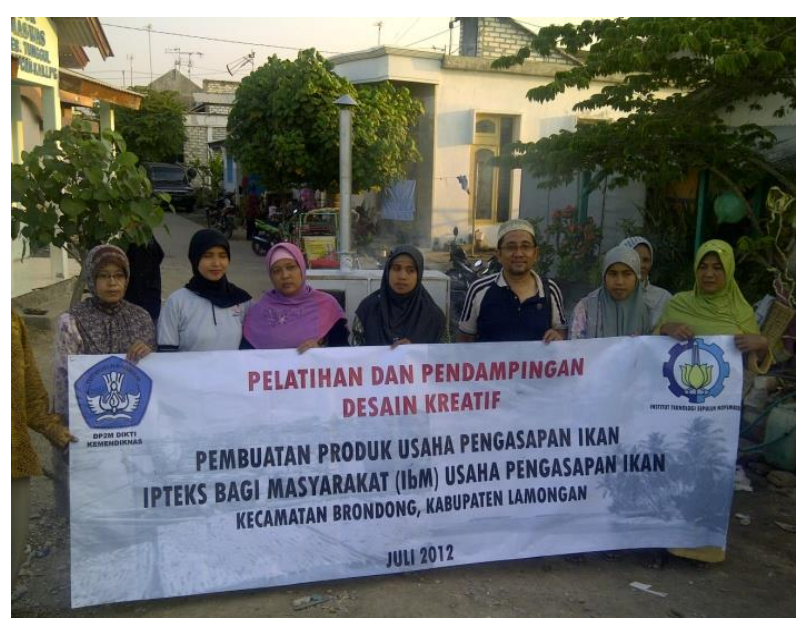

Fig 9. Participants of the program

The ESM (Ergonomics Smoke Machine) supports fisherwomen as a cottage and coastal industry and decreases the likelihood that women will be forced to seek jobs outside their community. Furthermore, the grassroots approach benefits the entire community. By adding the ESM to their product line, welder can increase their incomes and gain satisfaction from making and selling a product that helps their own people. Another benefit is that the welder can use their increased awareness of ergonomics to improve their own working methods.

The more obvious outcomes in health, productivity, and fish quality are accompanied by cultural and personal benefits (Figure 10). The women describe feeling enhanced pride in their identity as Brondong fisherwomen. The ESM enhances self-esteem and helps the indigenous people preserve their traditions.

The tools has already designed in proper way in order to have better understanding on ergonomics tools used, moreover the correlation between ergonomics approach, product design and community development. 


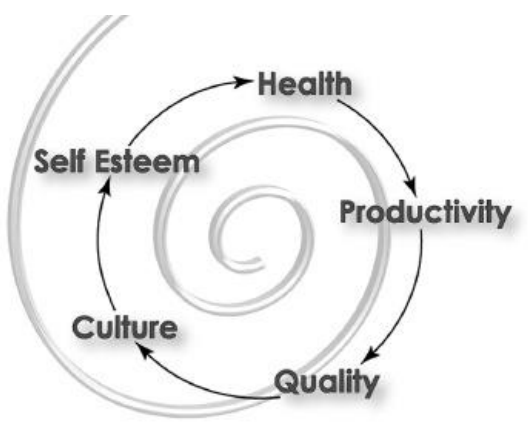

Fig 10. The elements of this ergonomics cycle of benefits apply universally, bringing all products an evolving sense of selfconfidence, a connection with their cultural heritage, and development of their unique creative gifts of local wisdom products [15].

\section{Conclusions}

From the results of community service programs, the following conclusions can be drawn:

a. Has implemented the implementation of Community Service in the form of skills training on Fish Curing Method with the following materials: Development of entrepreneurial spirit, Financial management, Creative packaging design, Implementation of mobile fishing tool and portable to improve fish processing so it can increase competitiveness

b. Increasing community self-reliance and providing community income through entrepreneurial activities.

c. Skilled in processing smoked fish.

d. Functioning as a means of trying for the community.

\section{Award Recognition}

This work on development of the ESM ergonomic smoke machine for fishermen has been recognized with an Indikatama Award for Innovating Technology Benefiting Humanity.

\section{Contribution and Collaboration of Research}

The ESM of this study contribute to society especially the people in the coastal area along the Indonesian coast. Since Indonesia possess the second longest coastal in the world while the Canada is longest one.

Author is actively developing ergonomics resources across the spectrum of art media, art cultures and technology. We invite and welcome with individuals and organizations that share a passion for exploring the link between ergonomics and human creativity, and for bringing ergonomics to cultures and economies where it has been underrecognized and undervalued.

Authors acknowledge funding support from Directorate General of Higher Education, Ministry of Technology Research and Higher Education, Republic of Indonesia

\section{References}

1. M. Tbrner, G. Blide, H. Eriksson, R. Kadefors, R. Karlsson, and I. Petersen, "Musculo-skeletal symptoms as related to working conditions among
Swedish professional fishermen," no. September, pp. 191-201, 1988.

2. M. Tisrner, R. Karlsson, S. Harald, and R. Kadefors, "Analysis of serious occupational accidents in Swedish fishery," vol. 21, 1995.

3. K. Kazmierczak, S. Erik, M. Forsman, and J. Winkel, "An integrated analysis of ergonomics and time consumption in Swedish ' craft-type' car disassembly," vol. 36, no. 2005, pp. 263-273, 2006.

4. A.-C. Falck and M. Rosenqvist, "What are the obstacles and needs of proactive ergonomics measures at early product development stages? - An interview study in five Swedish companies," Int. J. Ind. Ergon., vol. 42, no. 5, pp. 406-415, Sep. 2012.

5. S. Fulmer, "Ergonomic Exposure Case Studies in Massachusetts Fishing Vessels," vol. 18, pp. 10-18, 2002.

6. J. M. Lincoln, M. B. O. Connor, K. D. Retzer, R. D. Hill, T. D. Teske, C. C. Woodward, D. L. Lucas, P. D. Somervell, J. T. Burton, N. A. Mode, B. J. Husberg, and G. A. Conway, "Occupational Fatalities in Alaska: Two Decades of Progress , 1990-1999 and 2000-2009,” J. Safety Res., vol. 44, pp. 105-110, 2013.

7. M. A. Zytoon, "Occupational injuries and health problems in the Egyptian Mediterranean fisheries," Saf. Sci., vol. 50, no. 1, pp. 113-122, 2012.

8. et al Shaffril, "Adapting towards climate change impacts: Strategies for small-scale fishermen in Malaysia," Mar. Policy, vol. 81, no. December 2017, pp. 196-201, 2017.

9. B. Jackson, B. Neis, A. Canning, and S. Mackinnon, "Safety on Newfoundland's fishing wharves," vol. 60, pp. 1-12, 2013.

10. E. Mcguinness, H. L. Aasjord, I. B. Utne, and I. Marie, "Safety Scien ce Injuries in the commercial fishing fleet of Norway 2000 - 2011," Saf. Sci., vol. 57, pp. 82-99, 2013.

11. T. Thorvaldsen, "The importance of common sense : How Norwegian coastal fishermen deal with occupational risk," Mar. Policy, vol. 42, pp. 85-90, 2013.

12. N. M. Smith, S. Ali, C. Bo, and N. Collins, "Human health and safety in artisanal and small-scale mining: an integrated approach to risk mitigation," vol. 129, 2016.

13. E. Nurmianto, Ergonomi: Konsep Dasar dan Aplikasinya, 2nd ed. Surabaya: Guna Widya, 2004.

14. I. Z. Sutalaksana and A. Widyanti, "Anthropometry approach in workplace redesign in Indonesian Sundanese roof tile industries," Int. J. Ind. Ergon., vol. 53, pp. 299-305, 2016.

15. B. Y. K. Piegorsch, "An Ergonomic Bench for Indigenous Weavers," Ergon. Des., 2009.

16. G. A. Mirka, X. Ning, S. Jin, O. Haddad, and K. L. Kucera, "International Journal of Industrial Ergonomics Ergonomic interventions for commercial crab fi shermen," vol. 41, 2011. 